\title{
Deformation mechanisms and microplasticity of austenitic TRIP/TWIP steel under flyer plate impact
}

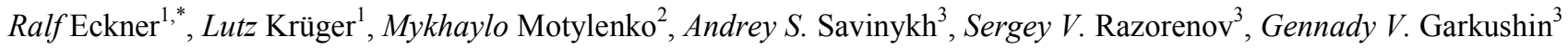 \\ ${ }^{1}$ Institute of Materials Engineering, Technische Universität Bergakademie Freiberg, Germany \\ ${ }^{2}$ Institute of Materials Science, Technische Universität Bergakademie Freiberg, Germany \\ ${ }^{3}$ Russian Academy of Sciences, Institute of Problems of Chemical Physics, Chernogolovka, Moscow Region 142432, Russia
}

\begin{abstract}
The focus of this study is on the deformation mechanisms of high-alloy cast austenitic TRIP/TWIP steel with the nominal composition Fe-16Cr-6Mn-6Ni. Due to its chemical composition, the material exhibits a low stacking-fault energy of $17.5 \mathrm{~mJ} / \mathrm{m}^{2}$ which facilitates the formation of the deformation-induced $\gamma(\mathrm{fcc}) \rightarrow \varepsilon$ (hcp) $\rightarrow \alpha^{\prime}$ (bcc) transformation. Consequently, the steel exhibits a tensile strength of $800 \mathrm{MPa}$ with fracture elongation of $55 \%$ under quasi-static loading. The experiments presented demonstrate the response of this steel to flyer-plate impact (FPI) at room temperature using two different test setups. In the first setup, laser interferometry measurements of the sample free surface were used for determination of the dynamic mechanical properties (Hugoniot elastic limit / HEL, spall strength) after impact with aluminium plates accelerated up to $650 \mathrm{~m} / \mathrm{s}$. In the second setup, an experimental shock testing device developed at the Freiberg High-Pressure Research Centre was used for impacting large cylindrical samples without the occurrence of spallation. Subsequently, microstructural investigations were carried out by scanning electron microscopy (SEM) and transmission electron microscopy (TEM) in combination with diffraction techniques and magnetic martensite measurements. Their results facilitate the representation of a complete image of deformation mechanisms during shock wave loading.
\end{abstract}

\section{Introduction}

Modern advanced high strength steels (AHSS) offer great potential for improving occupant safety in vehicle crash events as well as for lightweight modes of construction that reduce weight and energy consumption $[1,2]$. Such steels take advantage of the TRIP- and/or TWIP-effect (TRansformation Induced Plasticity or TWinning Induced Plasticity), which are both triggered by plastic deformation and depend strongly on the stacking-fault energy of the steel [3]. At relatively high stacking-fault energies $\left(>30 \mathrm{~mJ} / \mathrm{m}^{2}\right)$, the material deforms substantially due to the motion of dislocations. Stacking-fault energies between 20 and $30 \mathrm{~mJ} / \mathrm{m}^{2}$ favour the emergence of stacking-faults and deformation twins (TWIP effect). In steel with lower stacking-fault energy, the TRIP is evident associated as it is with the formation of $\alpha^{\prime}$-martensite. The necessary mechanical driving force for the transformation $\gamma \rightarrow \alpha^{\prime}$ is provided by the stress applied on the materials.

Both the temperature dependence and the strain-rate dependence of the mechanical properties are important factors. An increase in strain rate up to $\sim 10^{3} \mathrm{~s}^{-1}$ generally leads to a thermally activated increase in yield strength but a decrease in strain hardening, due to the adiabatic heating of the specimen [4]. When the strain rate is further increased to levels above $10^{4} \mathrm{~s}^{-1}$, the loading is characterized by the propagation of elastic and plastic waves through the material. The deformation over the entire specimen can no longer be considered as an equilibrium system, because stresses are transferred from one atom to another, in a similar manner to a pulse with a length of a few nanoseconds. The shock pulse also induces an expansion wave, at which point the material returns to ambient pressure. These so-called rarefaction or release waves generate a material flow against the direction of shock-wave propagation. Unlike in a fluid, energy dissipation occurs during wave propagation and the mechanical energy is converted to thermal energy, which makes the process irreversible [5].

Iron and steels have been the subject of numerous shock wave studies in the past. In particular, the polymorphic high-pressure phase transformation in iron from $\alpha$-Fe to $\varepsilon$-Fe has been investigated extensively [6, 7]. In steel with low stacking-fault energy, e.g., in metastable austenitic stainless steels, shock waves can cause additional martensitic transformation. Several studies on steels corresponding to the composition of AISI $304(\sim 18 \% \mathrm{Cr}, \sim 10 \% \mathrm{Ni})$ under strain rates of up to $10^{5} \mathrm{~s}^{-1}$ demonstrated the formation of stacking faults, shear bands, and deformation-induced martensite during single or repeated shock wave loading [8-12]. Their results confirm the presence of the $\gamma \rightarrow \varepsilon \rightarrow \alpha^{\prime}$-transition up to such high loading rates. The microstructural changes comprise the formation of slip bands with a high concentration of dislocations and stacking faults [13].

Corresponding author: ralf.eckner@iwt.tu-freiberg.de 
Subsequently, band intersections act as nucleation sites for $\varepsilon^{-}$and $\alpha$-martensite. It can also be assumed that higher loading rates induce significantly more deformation bands and intersections [14], thus accelerating martensite formation. At the same time, uniaxial compressive deformation [15] and adiabatic heating under shock conditions both impedes the martensitic transformation. However, martensite morphology and nucleation mechanisms under shock loading are comparable to lower strain rates [12].

The intention of the present study is to investigate the deformation mechanisms active under shock wave loading by flyer-plate impact in cast high-alloy $\mathrm{CrMnNi}$ TRIP/TWIP-steel. Detailed investigations of the microstructures developed were performed in order to explain the experimental results, with special focus on the martensitic transformation.

\section{Materials and methods}

Based on a patent-protected development [16], the chemical composition of the material examined, is listed in Table 1. According to the nominal concentrations of $\mathrm{Cr}, \mathrm{Mn}$, and $\mathrm{Ni}$, the steel is described as Fe16Cr-6Mn$6 \mathrm{Ni}$. Melting was performed in an induction furnace, and the material was subsequently cast in a copper mould under an argon atmosphere. The as-cast samples exhibited pronounced dendritic microstructures, which contained coarse austenitic grains with a size of between 100 and $1000 \mu \mathrm{m}$. Subsequently, specimens for shock loading tests were manufactured, i.e., plates with the dimensions $45 \mathrm{~mm} \times 45 \mathrm{~mm}$ × $5 \mathrm{~mm}$ along with cylindrical samples of $40 \mathrm{~mm}$ in diameter and $50 \mathrm{~mm}$ in height. The samples were solution-heat-treated at $1323 \mathrm{~K}$ $\left(1050{ }^{\circ} \mathrm{C}\right)$ for 30 minutes to retransform any martensite induced by previous machining.

Table 1. Chemical composition of cast high-alloy $\mathrm{CrMnNi}$ TRIP/TWIP-steel [wt.-\%].

\begin{tabular}{|c|c|c|c|c|c|}
\hline $\begin{array}{c}\text { Fe }+ \\
\text { others }\end{array}$ & C & Cr & Mn & Ni & Si \\
\hline Bal. & 0.03 & 15.5 & 6.1 & 6.1 & 0.9 \\
\hline
\end{tabular}

The flyer-plate experiments were carried out at the Institute of Problems of Chemical Physics (RAS) in Chernogolovka, Russia using samples of $\sim 5 \mathrm{~mm}$ in thickness, which were impacted at room temperature by commercially pure aluminium plates of $2 \mathrm{~mm}$ in thickness with an impact velocity of approximately $650 \mathrm{~m} / \mathrm{s}$ [17]. The impactor was launched by an explosive lens. Hence, the planar impact of the aluminium disk produced a shock wave in the target specimen and resulted in a uniaxial strain state, which refers to a three-dimensional stress state with deformation only in the direction of loading. Due to the high impact velocity, the timescale of deformation was a matter of microseconds. Therefore, the free surface velocity profiles were recorded using a VISAR laser Doppler velocimeter [7] with a time resolution of $\sim 1 \mathrm{~ns}$ and a space resolution of $\sim 0.1 \mathrm{~mm}^{2}$, giving a measurement accuracy of $\sim 5 \mathrm{~m} / \mathrm{s}$.

For the shock-loading experiments without spallation, the flyer-plate method was used with an explosive plane wave generator (see Fig. 1). The flyerplates were made of CrMnNi steel and measured $3 \mathrm{~mm}$ in thickness and $80 \mathrm{~mm}$ in diameter. The shock loading assembly was refined for complete sample recovery using the system developed by the EMI (Ernst MachInstitute) in Freiburg, Germany [18] and was originally developed for the synthesis of ultrahard ceramic materials $[19,20]$ and for the shock-wave treatment of natural samples in the Mbar range under reproducible conditions. This device is based on the principle of impedance correction along both the loading path and release path avoiding free adiabatic decompression [21]. Using different amounts of explosives, the shock pressures were set to $30,60,90$, and $120 \mathrm{GPa}$. Below the sample, a quenched and tempered (QT) steel plate was mounted with the benefit of low impedance differences and, thus, low wave reflections (a momentum trap). The entire explosive device was positioned in a sand bed. Due to the fixture of the samples, no spallation occurred during the shock-loading experiments.

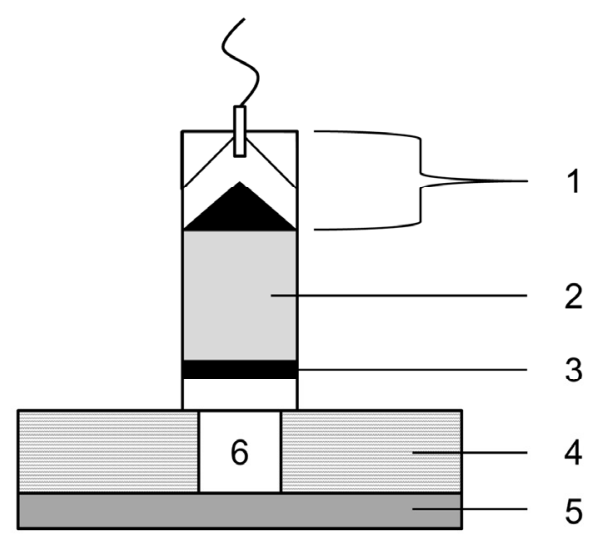

Fig. 1. Setup for shock experiments: (1) plane wave generator with electric detonator (PETN explosive) (2) C-4 explosive (3) CrMnNi steel flyer-plate, (4) Structural steel container (S355), (5) QT steel plate, (6) CrMnNi steel sample.

Subsequently, microstructural investigations were carried out by SEM (Carl Zeiss LEO 1530 at $20 \mathrm{kV}$ acceleration voltage) and TEM (JEM-2200FS at $200 \mathrm{kV}$ acceleration voltage) in combination with Electron backscatter diffraction (EBSD) and Selected area electron diffraction (SAED) techniques as well as magnetic martensite measurements.

\section{Results and discussion}

The determination of the dynamic strength characteristics of the investigated metastable austenitic cast steel was based on the VISAR signal recorded. The necessary physical material parameters for the corresponding calculations had to be determined first and are shown in Table 2. An overview of the calculations of the corresponding strength parameters for 
which the physical parameters are important can be found in $[17,22]$.

Table 2. Physical parameters of the Fe-16Cr-6Mn-6Ni cast steel investigated. ( $c_{\mathrm{el}}$ - longitudinal elastic sound speed, $c_{\mathrm{b}}$ - bulk sound speed).

\begin{tabular}{|c|c|c|c|c|}
\hline $\boldsymbol{E}$ & $\boldsymbol{v}$ & $\boldsymbol{c}_{\text {el }}$ & $\boldsymbol{c}_{\mathbf{b}}$ & $\boldsymbol{\rho}_{\mathbf{0}}$ \\
\hline 191 & 0.24 & $\begin{array}{c}5.72 \\
(\mathrm{~km} / \mathrm{s})\end{array}$ & $\begin{array}{c}4.65 \\
(\mathrm{~km} / \mathrm{s})\end{array}$ & $\begin{array}{c}7819 \\
\left(\mathrm{~kg} / \mathrm{m}^{3}\right)\end{array}$ \\
\hline
\end{tabular}

Fig. 2 shows the free surface velocity history obtained during flyer-plate impact testing for the metastable austenitic Fe-16Cr-6Mn-6Ni cast steel. The wave form obtained was somewhat typical for elasticplastic material behaviour, and contained information about the yield point and the fracture strength. First, the elastic precursor arrived at the free end, which determined the Hugoniot elastic limit (HEL). Thereafter, the surface velocity increased again, which was associated with plastic deformation and ended in the steady Hugoniot state. The subsequent drop in surface velocity was due to the release wave or rarefaction, which reduced the pressure on the material and led to spall fracture. The velocity pullback $\left(\Delta u_{\mathrm{fs}}\right)$ could be used to determine the spall fracture strength.

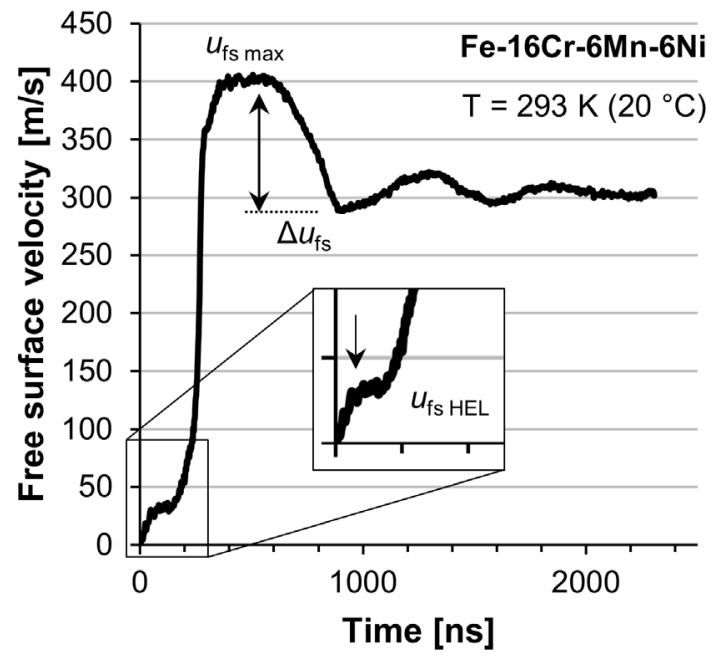

Fig. 2. Free surface velocity profile of Fe-16Cr-6Mn-6Ni cast steel impacted by an aluminium flyer plate at room temperature (5 mm sample thickness).

The results of the calculation of the mechanical properties using the free surface velocity data are presented in Table 3.

Table 3. Strength properties of the Fe- $16 \mathrm{Cr}-6 \mathrm{Mn}-6 \mathrm{Ni}$ steel investigated by flyer-plate impact: $\mathrm{u}_{\mathrm{fs} \max }-$ peak surface velocity, $u_{\mathrm{fs}} \mathrm{HEL}-$ elastic wave amplitude, $\sigma_{\mathrm{HEL}}-$ Hugoniot elastic limit, $\Delta u_{\mathrm{fs}}-$ velocity pullback before spall, $\sigma_{\text {sp. }}^{*}-$ spall strength.

\begin{tabular}{|c|c|c|c|c|}
\hline $\boldsymbol{u}_{\text {fs max }}$ & $\boldsymbol{u}_{\text {fs HEL }}$ & $\boldsymbol{\sigma}_{\mathbf{H E L}}$ & $\boldsymbol{\Delta} \boldsymbol{u}_{\text {fs }}$ & $\boldsymbol{\sigma}_{\text {sp. }}^{*}$ \\
\hline 400 & 23 & 0.51 & 134 & 2.69 \\
$(\mathrm{~m} / \mathrm{s})$ & $(\mathrm{m} / \mathrm{s})$ & $(\mathrm{GPa})$ & $(\mathrm{m} / \mathrm{s})$ & $(\mathrm{GPa})$ \\
\hline
\end{tabular}

The microstructure of the flyer-plate-impacted specimens was characterized by a large number of fine deformation bands and deformation-induced $\alpha$-martensite. The shock-wave loading caused the formation of lamellar band structures within the microstructure, which were evenly distributed throughout the specimen. These deformation bands ended at grain boundaries and were formed from bundles of separated dislocations and overlapping stacking faults. The sites of origin were preferentially located on active $\{111\}$ slip planes of the fcc crystal lattice, as these were the sites that experienced the highest shear stresses [23]. Typically, the deformation bands consisted of deformation-induced $\varepsilon$-martensite and twin structures, in which the intersections of the bands acted as nucleation sites for the formation of $\alpha$ '-martensite [24-25].

Fig. 3 shows the fine band structures within an austenite grain. Noticeable are the high band density and the narrow width of the bands. Nuclei of $\alpha^{\prime}$-martensite were often found within the deformation bands, as shown in Fig. 4, which acted as a barrier to further dislocation movement [26].



Fig. 3. Scanning TEM-micrograph of closely spaced deformation bands (a) in three different orientations (slip systems) within the $\gamma$-phase (b). The band intersections acted as nucleation sites for the formation of bcc $\alpha^{\prime}$-martensite (c).



Fig. 4. TEM-micrograph of a deformation band incorporating multiple lens-shaped $\alpha$-martensite nuclei (a). The lattice structures were derived from FFT analyses (b, c ,d). 
In order to find out to what extent the microstructural changes in the material were caused by the shock wave or the release wave during the flyer-plate impact, experiments were also carried out without spallation at different pressures. For this purpose, a comparison of the experimental parameters of the various shock tests is shown in Table 4. The experimental setup for shock tests without spallation allowed the introduction of higher shock pressures to the material, although the shock pulse duration remained approximately the same. This was important because significantly shorter or longer pulse times might have influenced martensite nucleation [27].

Table 4. Parameters of the shock-wave tests carried out: $d_{\text {Flyer }}$ flyer-plate thickness, $v_{\text {Flyer }}$ - flyer-plate velocity, $U_{\mathrm{S}}$ - shockwave velocity, $P$ - peak pressure, $t$ - load pulse duration.

\begin{tabular}{|c|c|c|c|c|c|}
\hline \multirow{2}{*}{ Test } & $\boldsymbol{d}_{\text {Flyer }}$ & $\boldsymbol{v}_{\text {Flyer }}$ & $\boldsymbol{U}_{\mathbf{S}}$ & $\boldsymbol{P}$ & $\boldsymbol{t}$ \\
\cline { 2 - 6 } & {$[\mathrm{mm}]$} & {$[\mathrm{km} / \mathrm{s}]$} & {$[\mathrm{km} / \mathrm{s}]$} & {$[\mathrm{GPa}]$} & {$[\mathrm{ns}]$} \\
\hline \multirow{2}{*}{ FPI } & 2 & 0.65 & 4.9 & 8 & 411 \\
\hline \multirow{3}{*}{$\begin{array}{c}\text { FPI (no } \\
\text { spallation) }\end{array}$} & 3 & 1.5 & 5.6 & 30 & 537 \\
\cline { 2 - 6 } & 3 & 2.5 & 6.5 & 60 & 459 \\
\cline { 2 - 6 } & 3 & 4 & 8.5 & 120 & 355 \\
\hline
\end{tabular}

The specimens were examined by SEM to obtain more detailed information about the microstructure of the samples impacted at higher pressures (30 - $120 \mathrm{GPa})$. As expected, numerous deformation bands were observed within the austenite grains. Previous investigations revealed that these deformation bands consist of bundles of stacking faults, twins, or $\varepsilon$ martensite. For a shock pressure of $30 \mathrm{GPa}$, the band structures were very thin and closely spaced but relatively homogenously distributed (see Fig. 5). With increasing shock pressure, the number and thickness of the deformation bands appeared to increase [28]. The bands evolved in two different orientations, but hardly any $\alpha^{\prime}$-martensite could be found at their intersections. It was assumed that up to $90 \mathrm{GPa}$, the deformation bands were very thin and, thus, that the driving force for the nucleation of $\alpha^{\prime}$-martensite was insufficient.

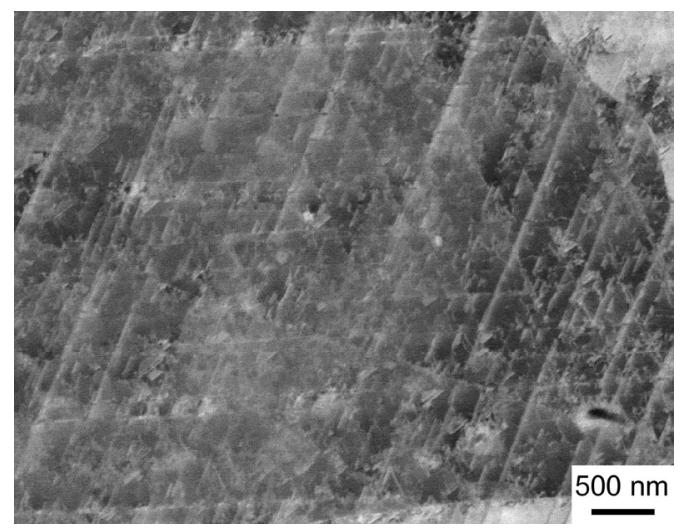

Fig. 5. SEM micrograph of the $30 \mathrm{GPa}$ shock-loaded sample, showing very fine deformation bands and individual stacking faults.
At the highest shock pressure of $(120 \mathrm{GPa})$ the deformation band thickness increased and $\alpha$ '-martensite nuclei were visible as dark lenses within the bands. Additional EBSD analyses, as shown in Fig. 6, found bcc and hcp phases within the deformation bands, which confirmed the presence of $\varepsilon$ - and $\alpha$ '-martensite. Hence, the $\varepsilon$-martensite acted as an intermediate phase from which $\alpha$-martensite arose, according to the transformation sequence $\gamma \rightarrow \varepsilon \rightarrow \alpha^{\prime}[23,26,28-31]$.

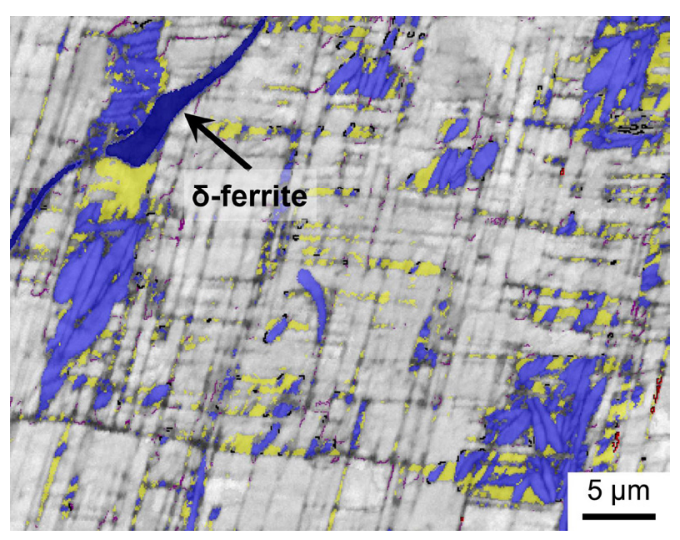

Fig. 6. Phase distribution after $120 \mathrm{GPa}$ shock loading measured by EBSD: gray - austenite (fcc) in band contrast, blue - $\alpha$ '-martensite (bcc), and yellow - $\varepsilon$-martensite (hcp).

In the following, the martensite phase fraction in the shock-exposed samples was also quantified via X-ray diffraction and magnetic measurements. The results are shown in Fig. 7 and Fig. 8. The spalled flyer-plate impact sample (8 $\mathrm{GPa}$ shock pressure) exhibited high volume fractions of $\alpha^{\prime}$-martensite (7 Vol-\%) and $\varepsilon$ martensite (26 Vol.-\%). In comparison with quasistatic tensile tests, those values corresponded to strain values of about 0.1 for the $\alpha$-martensite and $>0.3$ for the $\varepsilon$-martensite. The large $\varepsilon$-martensite fraction corresponded to the high deformation band density already mentioned, and was connected with high dislocation density and a considerable increase in strength and hardness.

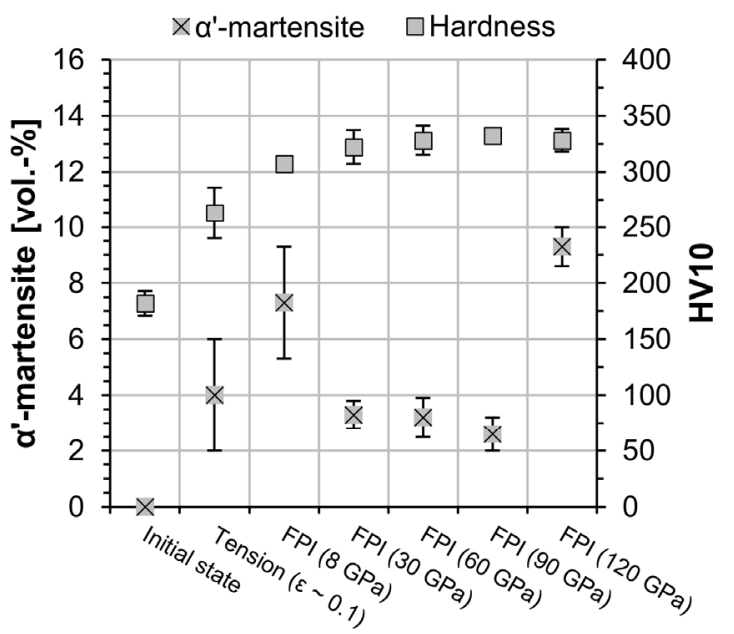

Fig. 7. Phase fraction of $\alpha^{\prime}$-martensite and the corresponding hardness values in the initial state, after quasistatic tensile loading and after different shock wave loading conditions. 
Fig. 7 shows the average hardness values measured under different pressure conditions. Shock loading at 90 GPa led to a maximum in average hardness, but the difference was within the experimental accuracy of the measurements. The hardness values correlated well with previous measurements performed on preshocked stainless steels, as summarized by Maloy et al. [32]. It is worth noting that the shock-exposed specimens experienced significant hardening when compared to the initial state or after tensile deformation. This was related to the shock-induced deformation band formation as an extremely localized effect, and is confirmed in the literature [33].

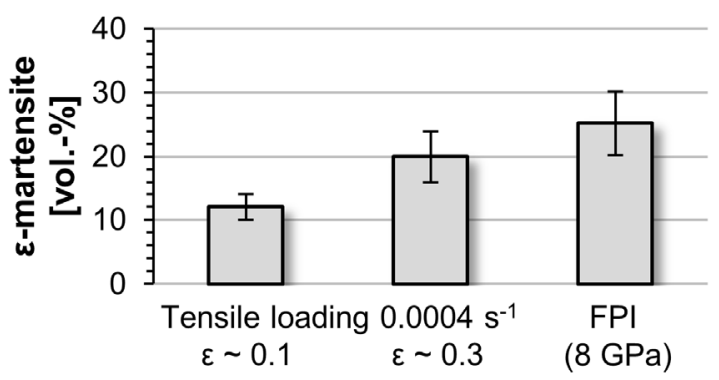

Fig. 8. Phase fraction of $\varepsilon$-martensite measured by XRD after quasistatic tensile loading (from [26]) and flyer-plate impact.

As a simple integral measure of strain hardening, the macroscopic hardness shows that the shock-wave loading induced a large amount of defects within the austenitic microstructure. Nevertheless, the timing of the deformation mechanisms could not be identified in this manner. The main difference between the experimental setups used was the impedance correction for the high pressure tests, which avoided the occurrence of spallation within the larger cylindrical sample. Thus, it was assumed that the material experienced only the passage of the planar shock wave without reflection of the pulse. Meyers et al. [34-36] show that the martensitic $\gamma \rightarrow \alpha$ transformation takes place primarily after reflection of the compressive wave on a free surface. The transformation is then triggered by the tensile reflected pulse and is favoured by the tensile hydrostatic component of the stress state. Moreover, the stress pulse increases $\mathrm{M}_{\mathrm{S}}$, the martensite start temperature, which corresponds to an increase in the thermodynamic driving force for the $\gamma \rightarrow \alpha^{\prime}$ transformation [15]. Johnson et al. [37] show the influence of stress state on the martensitic transformation in very effective manner. They carry out planar compressive shock tests on 304 stainless steel and measured approx. 8 vol.- $\% \alpha^{\prime}$-martensite after 20 to 120 $\mathrm{GPa}$ shock loading. On the other hand, they measure approx. $\quad 70$ vol.- $\% \quad \alpha^{\prime}$-martensite after cylindrical explosive loading with complex triaxial stress (strain) state in the same pressure range.

Thus, it can be stated that $\alpha^{\prime}$-martensite formation in metastable austenite is hindered during the shock-wave passage due to the uniaxial strain field. Still, localized deformation leads to the formation of thin and closely spaced deformation bands. During the release stage, their intersections act as nucleation sites for $\alpha^{\prime}$-martensite which is then favoured due to a higher $\mathrm{M}_{\mathrm{S}}$.

\section{Conclusions}

Based on the experimental results, Fig. 9 outlines the microstructural deformation mechanisms of metastable austenitic TRIP/TWIP steel during shock wave loading, which can be summarized as follows:

\section{1-D elastic deformation and post-yield flow}

Localized microplasticity based on a large number of stacking faults and thin deformation bands (planar dislocation glide). Slip occurs on several intersecting and closely-spaced planes, due to the very thin shock front and the uniaxial nature of the compression.

\section{3-D plastic deformation}

Progressive strain hardening due to static and dynamic Hall-Petch effect caused by dislocation separation, slip band formation, increasing deformation band density and the formation of $\varepsilon$-martensite and $\alpha^{\prime}$-martensite nucleation sites.

\section{Rarefaction}

An expanding wave follows the shock wave, which reduces the materials density. The tensile stress promotes the $\gamma \rightarrow \varepsilon \rightarrow \alpha^{\prime}$-transformation through an increase in the formation and intersection of deformation bands with subsequent martensite nucleation and growth. Internal cavitation occurs due to stresses generated by the interaction of stress waves and which exceed the local dynamic tensile strength of the steel. The coalescence of the cavities creates a fragment (spall) which is separated from the free end of the plate.

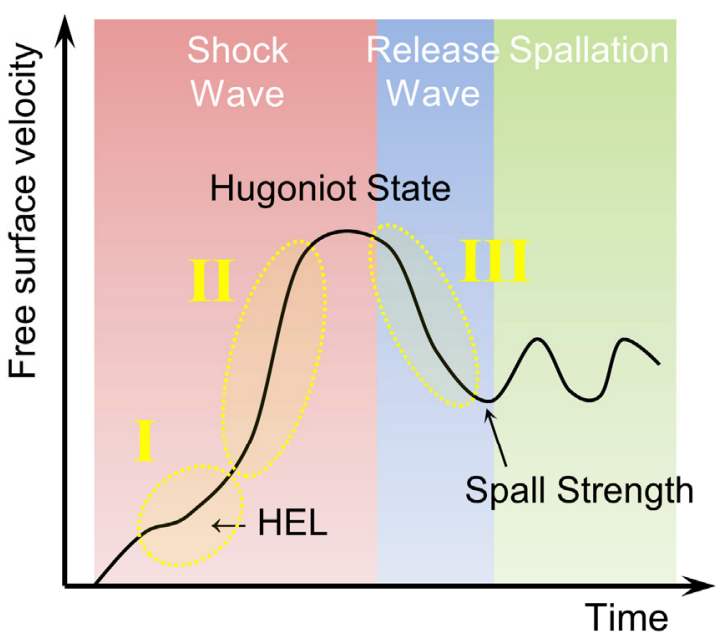

Fig. 9. Schematic representation of the deformation mechanisms of metastable austenitic TRIP/TWIP steel during different loading states under flyer-plate impact.

The authors gratefully acknowledge the Deutsche Forschungsgemeinschaft (the German Research Foundation DFG) for supporting this work, which was carried out within the framework of the CRC 799 project (Collaborative Research Center 799, B2). The build-up of the Freiberg Shock Wave Laboratory was financed by the Dr. Erich-Krüger foundation. The authors would like to thank Dr. T. Schlothauer for carrying out the shock-wave-loading tests on the cylindrical samples. 


\section{References}

1. O. Bouaziz, H. Zurob and M. Huang, Steel Res. Int. 84, 937-947 (2013)

2. N. Baluch, Z. M. Udin and C. S. Abdullah, Eng. Technol. Appl. Sci. Res. 4, 686-689 (2014)

3. A. Weiß, H. Gutte, A. Jahn and P. R. Scheller, Mat.wiss. u. Werkstofftech. 40, 606-616 (2009)

4. L. Krüger, S. Wolf, S. Martin, U. Martin, A. Jahn, A. Weiß and P. R. Scheller, Steel Res. Int. 82, 10871093 (2011)

5. M. B. Boslough and J. R. Asay, in J. Asay, M. Shahinpoor (eds.), High-pressure shock compression of solids, 7-42 (1993)

6. D. Bancroft, E. L. Peterson and S. Minshall, J. Appl. Phys. 27, 291-298 (1956)

7. L. M. Barker and R. E. Hollenbach, J. Appl. Phys. 45, 4872-4887 (1974)

8. V. I. Zel'dovich, A. E. Kheifets, N. Y. Frolova, A. K. Muzyrya and A. Y. Simonov, Phys. Met. Metallogr. 114, 1031-1037 (2013)

9. C. Sudha, T. N. Prasanthi, V. T. Paul, S. Saroja and M. Vijayalakshmi, Metall. Mater. Trans. A 43, 35963607 (2012)

10. K. Y. Luo, J. Z. Lu, Y. K. Zhang, J. Z. Zhou, L. F. Zhang, F. Z. Dai, L. Zhang, J. W. Zhong and C. Y. Cui, Mater. Sci. Eng. A 528, 4783-4788 (2011)

11. A. Y. Chen, H. H. Ruan, J. Wang, H. L. Chan, Q. Wang, Q. Li and J. Lu, Acta mater. 59, 3697-3709 (2011)

12. W.-S. Lee and C.-F. Lin, Scripta mater. 43, 777-782 (2000)

13. B. F. Wang, Z. L. Liu, X. Y. Wang and Z. Z. Li, Mater. Sci. Eng. A 610, 301-308 (2014)

14. K. Chen, C. Zheng, Z. Yuan, J. Lu, X. Ren and X. Luo, Mater. Sci. Eng. A. 587, 244-249 (2013)

15. J. R. Patel and M. Cohen, Acta Metall. 24, 531-538 (1953)

16. H. Gutte, M. Radke, P. R. Scheller and A. Weiß, Patent WO/2008/009722 (2008)

17. A. S. Savinykh, G. V. Garkushin, S. V. Razorenov, S. Wolf and L. Krüger, Combust. Explos. Shock Waves 51, 124-129 (2015)

18. K. Thoma, U. Hornemann, M. Sauer and E. Schneider, Meteorit. Planet. Sci. 40, 1283-1298 (2005)
19. T. Schlothauer, M. R. Schwarz, M. Ovidiu, E. Brendler, R. Moeckel, E. Kroke and G. Heide in S. V. Krivovichev (ed.), Minerals as Advanced Materials II, 375-388 (2012)

20. K. Keller, T. Schlothauer, M. Schwarz, G. Heide and E. Kroke, High Pressure Res. 32, 23-29 (2012)

21. T. Schlothauer, C. Schimpf, E. Brendler, K. Keller, E. Kroke and G. Heide, J. Phys.: Conf. Ser. 653, 1-12 (2015)

22. R. Eckner, B. Reichel, A. S. Savinykh, L. Krüger, S. V. Razorenov and G. V. Garkushin, Metall. Mater. Trans. A 47, 75-83 (2016)

23. A. Weidner, S. Martin, V. Klemm, U. Martin and H. Biermann, Scr. Mater. 64, 513-516 (2011)

24. J. Talonen and H. Hänninen, Acta Mater. 55, 61086118 (2007)

25. G. B. Olson and M. Cohen, J. Less-Common Met. 28, 107-118 (1972)

26. S. Martin, S. Wolf, S. Decker, L. Krüger and U. Martin, Steel Res. Int. 86, 1187-1196 (2015)

27. M. A. Meyers, Mater. Sci. Eng. 51, 261-263 (1981)

28. R. Eckner, L. Krüger, C. Ullrich, D. Rafaja, T. Schlothauer and G. Heide, Metall. Mater. Trans. A 47, 4922-4932 (2016)

29. S. Martin, S. Wolf, U. Martin, L. Krüger and D. Rafaja, Metall. Mater. Trans. A 47, 49-58 (2016)

30. K. Sato, M. Ichinose, Y. Hirotsu and Y. Inoue, ISIJ Int. 29, 868-877 (1989)

31. O. Grässel, L. Krüger, G. Frommeyer and L. W. Meyer, Int. J. Plast. 16, 1391-1409 (2000)

32. S. A. Maloy, G. T. Gray III, C. M. Cady, R. W. Rutherford and R. S. Hixson, Metall Mater. Trans. A 35A, 2617-2624 (2004)

33. A. H. Holtzman and G. R. Cowan in P. G. Shewmon, V. F. Zackay (eds.), Response of metals to high velocity deformation, 447-481 (1961)

34. M. A. Meyers, N. N. Thadhani, D. C. Ehrlich and P. S. DeCarli, in J. R. Asay, R. A. Graham, G. K. Straub (eds.), Shock Waves in Condensed Matter, 411-414 (1984)

35. A. Meyers and N. N. Thadhani, in Proc. 9th Intl. Conf. on High Energy Rate Fabrication, 90-97 (1986)

36. M.A. Meyers, N.N. Thadhani and S.N. Chang, J. de Physique 49, C3-355-362 (1988)

37. K. A. Johnson, L. E. Murr and K. P. Staudhammer, Acta metall. 33, 677-684 (1985) 